\title{
Relative Weight of Brown Trout and Lake Trout in Blue Mesa Reservoir, Colorado
}

\author{
Jessica Abbott \\ U.S. Air Force Academy \\ 2354 Fairchild Drive, USAF Academy, CO 80840, USA \\ Kerri Schmidt \\ U.S. Air Force Academy \\ 2354 Fairchild Drive, USAF Academy, CO 80840, USA \\ Michael Courtney (Corresponding author) \\ BTG Research \\ P.O. Box 84966, Baton Rouge, LA, 70884, USA \\ E-mail: Michael_Courtney@alum.mit.edu
}

Received: October 7, 2014 Accepted: November 25, 2014 Published: January 1, 2015

doi:10.5296/ast.v3i1.6813 URL: http://dx.doi.org/10.5296/ast.v3i1.6813

\begin{abstract}
Published data concerning the standard weight in lake trout (Salvelinus namaycush) and brown trout (Salmo trutta) have been established. The standard weights were used to compute relative weights for data collected in the spring and summer of 2011 for brown trout and lake trout in the Blue Mesa Reservoir, Colorado. The mean relative weight of a sample of 100 brown trout ranging in length from 260 to $432 \mathrm{~mm}$ was $71.72+/-0.90$, showing that the brown trout were in poor condition. The mean relative weight of a sample of 17 lake trout ranging in length from 387 to $689 \mathrm{~mm}$ was $86.57+/-2.40$, showing that the lake trout were also in poor condition. Using least squares regression, a best fit curve was determined for weight (W) vs. total length (L) in the brown trout, $\mathrm{W}(\mathrm{L})=1000(\mathrm{~L} / 517.49)^{2.5746}$, where $\mathrm{W}$ is in grams, and $\mathrm{L}$ is in millimeters.
\end{abstract}

Keywords: Relative weights, Fish condition, Lentic systems, Bioindicators, Predation, Overpopulation 


\section{Introduction}

Blue Mesa Reservoir is a clear mountain reservoir located in Gunnison County, Colorado. It is the largest body of water in Colorado. This reservoir is also home to the largest kokanee salmon fishery in the United States. Lately, samples from the reservoir have been used to evaluate abundance and body condition of several different species of fish (Curecanti, 2011). According to the samples taken, the abundant lake trout population have been causing a decline in the kokanee salmon population. The decline in the number of kokanee salmon has affected the lake trout by stunting their growth from lack of food to support their population (Johnson, 2011).

Relative weight is an indicator of plumpness defined as 100 times the actual weight divided by the expected weight (Anderson and Neumann, 1996). It suggests the abundance of food available for each member of the population relative to the energy demands. This study reports the average relative weight of a sample of 100 brown trout and 17 lake trout as well as a weight vs. length relationship for the sample of brown trout.

\section{Method}

The lake trout and brown trout for the study were caught by sport anglers and measured during creel surveys at the reservoir's boat ramps in the spring and summer 2011. Accuracy for the measurements of the fish were $+/-2.3$ grams for their weight and $+/-3 \mathrm{~mm}$ for the total length. The weight-length relationship in fish is represented by the improved model $W(L)=$ $1000\left(\mathrm{~L} / \mathrm{L}_{1}\right)^{\mathrm{b}}$, where L represents the total length (in mm) and $\mathrm{W}$ is the weight (in g). This model has been shown to yield smaller uncertainties in the parameters $\mathrm{L}_{1}$, which is the typical length of the fish weighing $1 \mathrm{~kg}$, and the exponent b. (Courtney et al., 2014; Dexter et al., 2011; Keenan et al., 2011; Cole-Fletcher et al., 2011).

The equivalent parameter $a$ from the traditional model $\mathrm{W}=\mathrm{aL}^{\mathrm{b}}$ can be computed as $1000 \mathrm{~L}_{1}^{-\mathrm{b}}$. The weight-length relationship is computed for brown trout using this model, but not for lake trout, because the exponent would be dominated by the single longest fish due to the sample size. The mean relative weight for brown trout as well as lake trout were calculated (relative to standard weights from Hyatt and Hubert (2001) for brown trout and from Anderson and Neumann (1996) for lake trout), and the reported uncertainties are the standard errors of the mean. Some authors have taken exception to standard weights developed with the regression line percentile method (Gerow et al., 2004; Gerow, 2010); however, the authors of the present study are unaware of a better comparison standard for these species.

\section{Results}

Figure 1 shows the graph of weight vs. length for 100 brown trout along with the best-fit weight vs. length curve and the standard weight curve. Most of the fish in the sample were significantly below the standard weight curve, and many were also below the best-fit curve for the $25^{\text {th }}$ percentile weight vs. length data in Carlander (1969). The exponent in the best-fit model for the present study, $\mathrm{W}(\mathrm{L})=1000\left(\mathrm{~L} / \mathrm{L}_{1}\right)^{\mathrm{b}}$ is $\mathrm{b}=2.5746+/-0.1235$ which shows allometric growth of brown trout in the reservoir with the fish tending to become relatively more slender as they grow longer. The parameter $\mathrm{L}_{1}$, which represents the typical length of a fish weighing $1 \mathrm{~kg}$ is $517.49 \mathrm{~mm}+/-8.44 \mathrm{~mm}$. This is much longer than the $450 \mathrm{~mm}$ which is 


\section{Macrothink

the more common length of a fish weighing $1 \mathrm{~kg}$ (Carlander 1969). As a bioindicator, such a large value of $L_{1}$ suggests poor fish condition (Courtney et al., 2014).

Figure 2 shows relative weight vs. length for 100 brown trout. Relative weights vary from 37.5 to 96.7 , with an average of $71.72+/-0.90$. Simpkins et al. (2003) found that juvenile rainbow trout have a significant risk of mortality when their condition index falls below 80 . The absence of many brown trout with relative weights below 60 suggests that a relative weight below 60 might have a high risk of mortality for brown trout in this length class. Relative weight can depend on length as the forage ability depends on the preferred food sources of fish as they grow. Figure 2 shows an apparent trend of decreasing relative weight with length. Figure 3 shows a histogram of relative weights in brown trout.

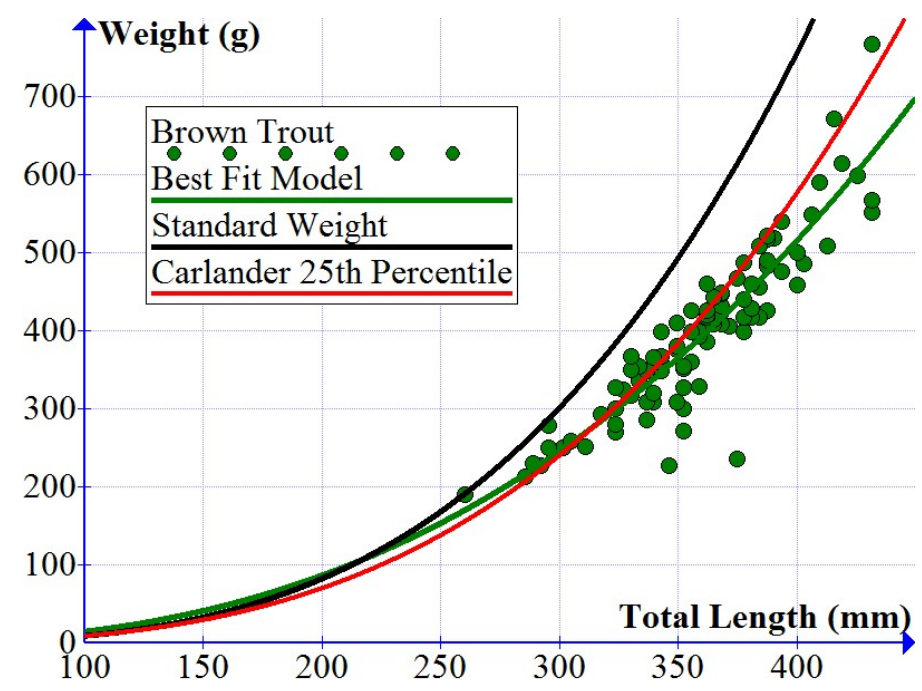

Figure 1. Weight vs. total length for brown trout in Blue Mesa Reservoir with the best fit weight-length curve, as well as the standard weight curve for brown trout (Hyatt and Hubert, 2001) and the best-fit line to the $25^{\text {th }}$ percentile data from Carlander (1969).

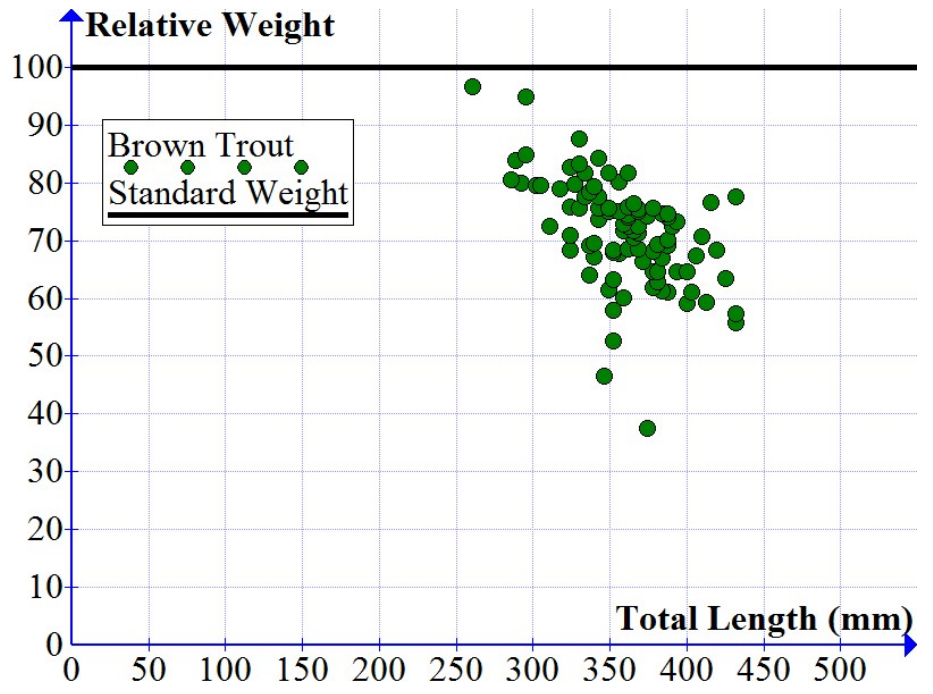

Figure 2. Relative weight vs. length brown trout in Blue Mesa Reservoir 


\section{1) Macrothink}

Aquatic Science and Technology

ISSN 2168-9148 2015, Vol. 3, No. 1

Figure 4 shows relative weight vs. length for 17 lake trout. Relative weights vary from 71 to 112 , with an average of $86.57+/-2.40$. It is notable that the 16 lake trout below or near $500 \mathrm{~mm}$ in length all have relative weights below 100 , and that the only specimen with a relative weight above 100 is much longer at $689 \mathrm{~mm}$.

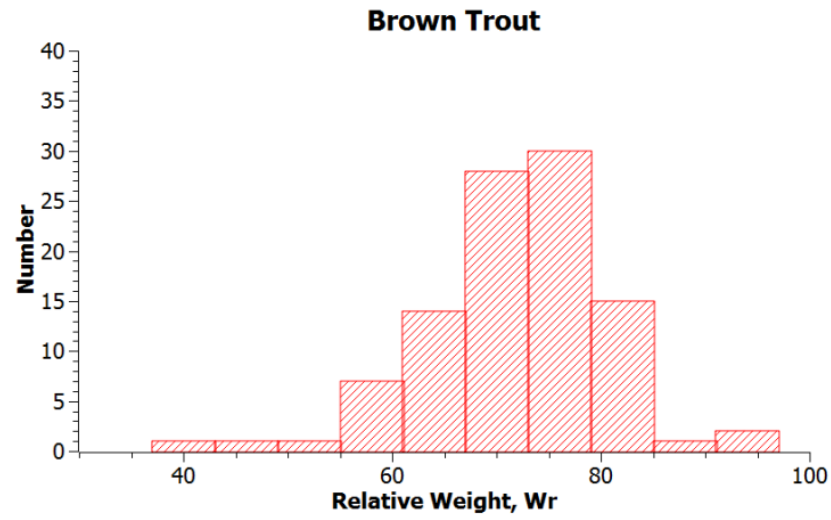

Figure 3. Histogram of relative weights for brown trout

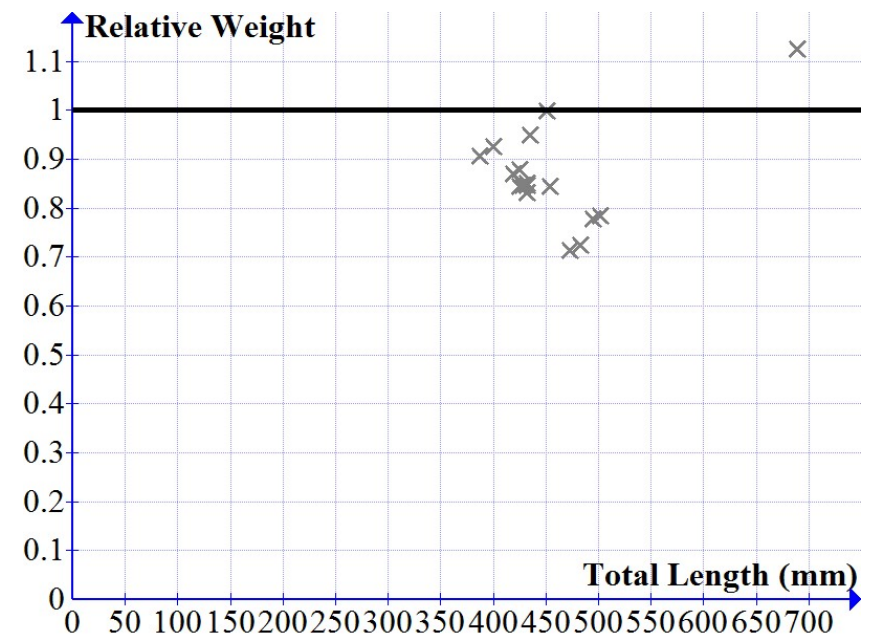

Figure 4. Relative weight vs. length for lake trout in Blue Mesa Reservoir

\section{Discussion}

In Blue Mesa Reservoir, the kokanee salmon population has been significantly reduced in recent years (Johnson, 2011). Increasing weight loss in lake trout coincides with population declines in kokanee salmon. This suggests that the kokanee salmon are an important food source for larger lake trout. Stomach content studies have confirmed heavy predation of kokanee salmon by lake trout, and a number of fisheries are finding it challenging to balance lake trout with kokanee salmon and rainbow trout fisheries (Johnson \& Martinez, 2000), since in the absence of other prey species (or few prey species as easy to catch and abundant as kokanee salmon and rainbow trout) the lake trout make it prohibitively expensive for wildlife managers to keep stocking sub-catchable fish only to have them eaten by the lake trout. 


\section{MInstitute ${ }_{\text {Int }}^{\text {Macrothink }}$}

The small sample size of lake trout does not allow for definitive conclusions in isolation, but there is general agreement with a much larger study (Johnson, 2011) which supports some observations. These results are consistent with Johnson (2011) whose findings for lake trout in Blue Mesa Reservoir document a rapid increase in relative weight as fish get longer and find very few lake trout under $500 \mathrm{~mm}$ long with relative weights above 100; whereas, specimens with relative weights above 100 are common in most years for lengths above $650 \mathrm{~mm}$. The number of plump lake trout in Johnson's findings (see Figure 4, Johnson, 2011) was small in 2009, but the relative weight for the longer lake trout was shown to increase in 2010 and 2011. These trends are ascribed to an overabundance of lake trout below $965 \mathrm{~mm}$ long, because the shorter lake trout eat mostly smaller fish for which there is too much competition with other small lake trout and the abundant brown trout in the reservoir. Once lake trout are large enough to eat the larger and abundant kokanee salmon in the reservoir, their relative weight quickly rises above 100. Johnson's work shows that relative weights above 130 are possible for the longer lake trout in the most productive years $(2000,2001,2002,2006)$. The Colorado Division of Wildlife seems to be attempting to manage the fishery to once again realize the potential for these fat lake trout.

An important finding of the present study is the poor condition of the brown trout. The low relative weight of the brown trout and the additional comparison with the $25^{\text {th }}$ percentile curve from Carlander (1969) suggest that the observation is not an artifact of how the standard weight curve was developed or attributable to a length-related bias in the curve. The brown trout seem to be more capable than rainbow trout and kokanee salmon of self-sustaining reproduction in Blue Mesa Reservoir (and the streams flowing into it) and also seem to be better than kokanee salmon and rainbow trout at avoiding predation from lake trout. As a result, the brown trout themselves have become overpopulated and unable to maintain optimal weights with the available food sources.

Though earlier studies had much smaller sample sizes, brown trout have consistently demonstrated low relative weights (69-85) in Blue Mesa Reservoir from 1994 to 2002 (Johnson \& Koski, 2005). Documentation of such low relative weights over such a long period with no stocking of this species suggests sufficient health and fecundity at these low relative weights to maintain a self-sustaining population. The lower tail in the histogram in Figure 3 shows that survivability becomes likely for $\mathrm{Wr}<60$. Selection pressure over time may have yielded brown trout population genetics in the reservoir that are more capable of surviving and successfully reproducing at lower relative weights. Distributions of relative weights in most populations are unlikely to be normally distributed (Gaussian) or even symmetric. Excessive thinness reducing survival chances provides a much harder lower limit. In contrast, increasing plumpness does not significantly reduce survival chances, and the relative weight distribution can easily have a much longer tail at high relative weights than it can at low relative weights.

Colorado Parks and Wildlife has become very aggressive in removing overpopulated lake trout in attempts to balance the fishery, both removing the limit on the number of smaller lake trout that can be kept by sport anglers and with netting operations. Perhaps aggressive management to reduce the numbers of brown trout is needed as well. If aggressive management is 
prohibitively expensive, liberal limits for anglers would be a positive step toward reducing abundance and increasing body condition.

\section{Acknowledgements}

The authors are grateful to BTG Research (www.BTGResearch.org) for supporting this work and to Joshua Courtney for valuable assistance weighing and measuring the fish. Joshua also brought the Simpkins 2003 reference to our attention and provided useful comments on the manuscript. The authors are also grateful to Dr. Brett Johnson (CSU) and Dr. Rich Marchand (USAFA/DFMS) for useful comments on the manuscript.

\section{References}

Anderson, R. O., \& Neumann, R. M. (1996). Length, Weight, and Associated Structural Indices. In Murphy B. E. \& Willis D. W. (Eds.), Fisheries Techniques (2nd ed. pp. 461-480). American Fisheries Society.

Carlander, K. D. (1969). Handbook of freshwater fishery biology (volume 1). Ames, Iowa: The Iowa State University Press.

Cole-Fletcher, S., Marin-Salcedo, L., Rana, A., \& Courtney, M. (2011). Errors in Length-Weight Parameters at FishBase.org. Cornell University Library.

Courtney, Y., Courtney, J., \& Courtney, M. (2014). Improving Weight-Length Relationships in Fish to Provide More Accurate Bioindicators of Ecosystem Condition. Aquatic Science and Technology, 2(2), 41-51. http://dx.doi.org/10.5296/ast.v2i2.5666

Curecanti National Recreation Area (U.S. National Park Service). U.S. National Park Service Experience Your America. National Park Service U.S. Department of the Interior, 14 Sept. 2011. Web. Oct. 2011. Retrieved from http://www.nps.gov/cure/index.htm

Dexter, M., Van Alstine, K., Courtney, M., \& Courtney, Y. (2011). Demonstrating an Improved Length-weight Model in Largemouth Bass, Chain Pickerel, Yellow Perch, Black Crappie, and Brown Bullhead in Stilwell Reservoir, West Point, New York. Cornell University Library.

Gerow, K. G. (2010). Biases with the regression line percentile method and the fallacy of a single standard weight. North American Journal of Fisheries Management, 30, 679-690. http://dx.doi.org/10.1577/m09-024.1

Gerow, K. G., Hubert, W. A., \& Anderson-Sprecher, R. C. (2004). An alternative approach to detection of length-related biases in standard weight equations. North American Journal of Fisheries Management, 24, 903-910. http://dx.doi.org/10.1577/m03-035.1

Hyatt, M. W., \& Hubert, W. A. (2001.) Proposed standard-weight (Ws) equation and length-categorization standards for brown trout (Salmo trutta) in lentic habitats. Journal of Freshwater Ecology, 16(1), 53-56. http://dx.doi.org/10.1080/02705060.2001.9663787

Johnson, B. (2011). Sustaining Kokanee and Lake Trout at Blue Mesa Reservoir. Home. Colorado State University. Web. Oct. 2011. Retrieved from http://warnercnr.colostate.edu/ brett/lab/coldwater/BMR_MAC_KOK_000.htm 


\section{Macrothink}

Aquatic Science and Technology

ISSN 2168-9148 2015, Vol. 3, No. 1

Johnson, B. M., \& Koski, M. L. (2005). Reservoir and food web dynamics at Blue Mesa Reservoir, Colorado, 1993-2002. Final report, US Bureau of Reclamation, Grand Junction, Colorado.

Johnson, B. M., \& Martinez, P. J. (2000). Trophic economics of lake trout management in reservoirs of differing productivity. North American Journal of Fisheries Management, 20, 127-143. http://dx.doi.org/10.1577/1548-8675(2000)020<0127:TEOLTM>2.0.CO;2

Keenan, E., Warner, S., Crowe, S., \& Courtney, M. (2011). Length, Weight, and Yield in Channel Catfish, Lake Diane, MI. Cornell University Library.

Simpkins, D. G., Hubert, W. A., Martinez Del Rio, C., \& Rule, D. C. (2003). Physiological responses of juvenile rainbow trout to fasting and swimming activity: effects on body composition and condition indices. Trans. American Fisheries Society, 132, 576-589. http://dx.doi.org/10.1577/1548-8659(2003)132<0576:PROJRT>2.0.CO;2

Weitendorf, B. (2011). Kentucky Lake Fishing Measurement, Lake Barkley Fishing Measurement. Kentucky Vacations at Kentucky Lake \& Lake Barkley. Kentucky Lake Fishing Measurement. $\quad$ Web. $\quad$ Oct. $2011 . \quad$ Retrieved from http://www.kentuckylake.com/fishing/measurement.shtml

\section{Copyright Disclaimer}

Copyright for this article is retained by the author(s), with first publication rights granted to the journal.

This is an open-access article distributed under the terms and conditions of the Creative Commons Attribution license (http://creativecommons.org/licenses/by/3.0/). 